\title{
ENTRE LABORIOSOS E CONTEMPLATIVOS: O PAPEL DAS NOÇÓES DE TRABALHO E PREGUIÇA NO ENSAIO SOBRE A ORIGEM DAS LÍNGUAS, DE ROUSSEAU ${ }^{1}$
}

Thiago Vargas $^{2}$

\begin{abstract}
Resumo: No Ensaio sobre a origem das linguas, texto publicado postumamente, em 1781, Rousseau reflete sobre certos aspectos da conformaçáo antropológica e social, tendo em vista as diferentes configurações climáticas e geográficas nas quais os homens se encontram. O objetivo do artigo será examinar a importância das noçôes de trabalho e preguiça sobre elementos que, no Ensaio, constituem a antropologia desenvolvida por Rousseau. Para isso, buscaremos demonstrar como as diferentes dificuldades impostas pela natureza exigem variadas respostas aos obstáculos do meio ambiente. Estabelecendo uma polarização entre o Norte e o Sul, através de uma descrição das múltiplas espécies de trabalho, veremos como tais atividades moldarão, à sua maneira, as diferentes línguas e paixôes que caracterizam os indivíduos setentrionais e do merídio: se, no Norte, o trabalho recalca as paixôes, no Sul, encontramos uma condição que melhor se harmoniza com a preguiça natural do homem, atributo antropológico essencial ao sistema natural proposto por Rousseau. Finalmente, salientaremos como a importância do trabalho como resposta às diferentes condiçôes climático-geográficas também se faz sentir na formação dos povos, criando condiçôes materiais e espaços possíveis de convivência, tornando-se um elemento essencial no composto que forma a gênese antropológica e social de Rousseau.
\end{abstract}

Palavras-chave: Trabalho. Ócio. Ensaio sobre a origem das línguas. Rousseau. Antropologia.

\section{INTRODUÇÃo}

Ao apresentar, no Discurso sobre a origem da desigualdade, uma gênese e uma história do trabalho, Rousseau examina como o homem, abandonando um primeiro momento do estado de natureza no qual a indolência opera como atributo fundamental ${ }^{3}$, paulatinamente desenvolve modos de vida que comportam diversas formas de trabalho, e diferentes usos da técnica e de

${ }^{1}$ http://dx.doi.org/10.1590/S0101-31732018000100005 Este artigo é dedicado aos amigos e às amigas do Grupo de Estudos Rousseau - USP.

2 Doutorando em Filosofia pela USP, São Paulo, SP - Brasil. Bolsista Capes, Paris 1. E-mail:thivargas01@ yahoo.com.br.

${ }^{3}$ Jean Starobinski denomina esse período de uma fase de "ociosidade paradisíaca" (STAROBINSKI, 1964). Jacques Derrida ressalta a importância da indolência, no quadro do primeiro estado de natureza, ao argumentar que "[...] a indolência natural do homem bárbaro não é um caráter empírico entre outros. É uma determinação originária indispensável ao sistema natural. Ela explica que o homem não pudesse sair espontaneamente da barbárie e de seu século de ouro; ele não possuía dentro de si movimento para ir mais adiante. O repouso é natural.” (DERRIDA, 1967, p. 362-363). 
instrumentos. Com a sucessão de períodos e fundamentos que caracterizam cada uma das etapas que compóem o estado de natureza histórico (Luiz Roberto Salinas Fortes refere-se aos "diferentes graus intermediários" (SALINAS FORTES, 2007, p. 67-68) que se encontram entre o puro estado de natureza e o estado de civilização, dividindo esse intervalo de tempo em cinco grandes eventos ou estruturas), Rousseau buscará descrever e elaborar a explicação do surgimento de um conjunto de instituiçóes e realidades, culminando com a instauraçáo da divisáo social do trabalho e o pacto proposto pelo rico.

Publicado postumamente, em 1781, o Ensaio sobre a origem das línguas, por sua vez, situa-nos em um cenário distinto daquele primeiro estado de natureza descrito no Segundo discurso: com os indivíduos já saídos da ociosidade paradisíaca, conhecedores de uma técnica iniciada e empenhados em uma labuta manual e primitiva, o texto já parte do momento no qual os primeiros grupos começam a surgir e as famílias arriscam suas primeiras formaçôes. Nesse sentido, estabelecido o salto "de épocas", no interior de cada um dos textos, Starobinski tece a seguinte ponderação:

Contrariamente ao Discurso, o Ensaio náo remonta até a imagem hipotética do homem do primeiro estado de natureza, ainda solitário, privado de todas as faculdades que ele adquirirá pelo trabalho e pela reflexão, reduzido somente à virtualidade de uma liberdade e de uma perfectibilidade que ele exercerá, sob a provocaçáo das circunstâncias, no curso de sua história ulterior. O Ensaio, situando mais tarde os "primeiros tempos", parte do reconhecimento recíproco dos indivíduos que começam a se agrupar. (STAROBINSKI, 1995, p. CLXXIII, grifo nosso).

Nessa leitura, o trabalho precede (e é condição) do desenvolvimento das capacidades do homem. A história do desenvolvimento das faculdades humanas, bem como a história da razão, ocorre em paralelo com a história do trabalho: a experiência fornece aos sentidos diversos objetos, fazendo com que a percepção, operando nas sutilezas e nuances das diferenças que distinguem um objeto do outro, pouco a pouco estabeleça comparaçóes e crie uma rede de ligação entre os objetos conhecidos e desconhecidos. Assim, "[...] aquele que viu somente um objeto não tem comparaçôes a fazer [...] Mas, à medida que um objeto novo nos impressiona queremos conhecê-lo e procuramos relação entre ele e os que já conhecemos." (ROUSSEAU, 1995, p. 396). E, desse modo, será a partir do desenvolvimento gradual da comparação de ideias que nascerá a reflexão: "[...] a reflexáo nasce das ideias comparadas, e é a pluralidade de ideias que leva a compará-las.” (ROUSSEAU, 1995, p. 396). 
Ocorridas as primeiras catástrofes naturais, o quadro estático de isolamento e inércia do primeiro estado de natureza se rompe, dando início a uma fase de oposição do trabalho frente às adversidades naturais; os acidentes da natureza são um elemento fundamental que estabelece a ocasião propícia para os primeiros encontros, as iniciais causas de aproximação entre os homens:

As associaçóes de homens são, em grande parte, obra dos acidentes da natureza - os dilúvios particulares, os mares extravasados, as erupçóes dos vulcóes, os grandes tremores de terra, os incêndios despertados pelo raio e que destroem as florestas, tudo que atemorizou e dispersou os selvagens de uma regiáo, depois reuniu-os para reparar em conjunto as perdas comuns. (ROUSSEAU, 1995, p. 402).

As adversidades da natureza ocasionam, portanto, a proximidade entre os indivíduos que, para repararem as perdas através do trabalho comum, associam-se, ainda que de maneira efêmera e fugaz, em pequenos grupos. À medida que progressivamente passa a estabelecer relação entre objetos, a comparação conduz o homem a observar não apenas as coisas ou os animais, mas também os outros homens. $\mathrm{O}$ homem gradualmente passa a enxergar-se no outro, a reconhecer-se no outro, isto é, a perceber seu semelhante como seu igual. Somente após essa transição, e uma vez o trabalho e a técnica tendo instaurado determinadas condiçôes materiais, é que as famílias poderão iniciar sua formação.

Dessa forma, iniciado o movimento histórico do estado de natureza, no qual o ócio, frente às necessidades, deverá dar lugar à atividade, surgirão então novos modos de vida que se desenvolverão gradualmente: "[...] a indústria humana se estende com as necessidades que a fizeram nascer." (ROUSSEAU, 1995, p. 399). Para explicar esse desenvolvimento, Rousseau recorre a uma divisão tripartite devedora de uma tradição ${ }^{4}$, que é então evocada, no Ensaio,

\footnotetext{
${ }^{4}$ A divisão tradicional remonta aos pensadores e historiadores da antiguidade, como nos lembra Victor Goldschmidt, sempre em referência às reflexôes de Lucien Febvre, em seu livro La terre et l'évolution humaine. Poderíamos fornecer como exemplo, dentre esses autores da antiguidade, a seguinte passagem da Política de Aristóteles: "[...] há grandes diferenças nos modos de vida dos homens. Os mais indolentes são pastores (já que a alimentação que os animais domésticos lhes fornecem é obtida sem fadiga ou esforço; mas os rebanhos necessariamente tendo que se deslocar de lugar por conta do pasto, os próprios homens são obrigados a acompanhá-los, como se cultivassem alguma espécie de terra dotada de vida). Outros homens vivem da caça, e cada homem vive de diferentes ou determinados gêneros de caça: alguns, por exemplo, vivem de banditismo [brigandage]; outros de pesca - são aqueles que habitam as margens dos lagos, dos pântanos, dos rios ou de mares repletos de peixe e onde a pesca é possível. Outros, ainda, alimentam-se de pássaros ou animais selvagens. Mas, de maneira geral, a espécie humana vive sobretudo da terra e da cultura de seus produtos. É esta, portanto, a enumeração
} 
para explicar as diferenças entre as formas de subsistência e, em ligação direta a essas, a distância de cada período em relação ao estado social. ${ }^{5}$

O primeiro gênero de vida é classificado, em relação à subsistência, como o da caça e da pesca e, em relaçáo ao estado social, como o estado dos selvagens. Esse primeiro estágio "[...] emprega o corpo para a força, a alma para a coragem, a astúcia, enrijece o homem o torna feroz." (ROUSSEAU, 1995, p. 399). Tornam-se caçadores os mais diligentes e ativos, de constituição física mais forte; assim, "[...] aqueles que sempre andavam à frente somente podiam viver de frutos e da caça: tornaram-se caçadores, violentos, sanguinários; depois, com o decorrer dos tempos, guerreiros, conquistadores, usurpadores." (ROUSSEAU, 1995, p. 399). Embora reunidos em grupos, as relaçóes não eram seguras e nem duradouras. "Nada conhecendo, tudo temiam: atacavam para se defender" (ROUSSEAU, 1995, p. 395) e não possuíam, finalmente, nenhuma "[...] ideia de fraternidade comum.” (ROUSSEAU, 1995, p. 395).

Por sua vez, o segundo gênero é denominado como estado dos bárbaros, e é caracterizado pela arte pastoral, “[...] mãe do repouso e das paixôes ociosas” (ROUSSEAU, 1995, p. 400), a que melhor basta a si mesma. É composta por um maior contingente de pessoas, que, no primeiro estágio, no qual o indivíduo, "[...] menos ativo e mais passivo, desde que pode parou, reuniu o gado, cercou-o e tornou dócil a voz do homem. Para alimentá-lo, aprendeu a guardá-lo e a multiplicá-lo." (ROUSSEAU, 1995, p. 399). Após a intensa agitação e nomadismo que caracterizam as primeiras horas da saída do estado de natureza da ociosidade paradisíaca, marcada pela incessante luta contra os obstáculos, a inquietação e a atividade contínuas dão lugar ao repouso e à sedentarização, os quais farão emergir novos sentimentos. Mais propícia à aproximação dos homens e

completa dos diferentes modos de vida, aquelas ao menos cuja atividade produtiva é autônoma, e que, para obter sua alimentação, não necessitam nem das trocas nem do comércio: tal é o gênero de vida do pastor, do agricultor, do salteador [brigand], do pescador, do caçador." (ARISTÓTELES, 1962, p. 51-52, 1256a30 a 1256b).

${ }^{5}$ Rousseau utiliza os seguintes termos: em relação às necessidades de subsistência, "[...] são três as maneiras de viver possíveis para o homem" (ROUSSEAU, 1995, p. 399), e escreve, em seguida, "[...] à divisão precedente se relacionam os três estados do homem considerado em relação à sociedade" (ROUSSEAU, 1995, p. 400). A essa relação adiciona-se, ainda, aquela referente às diferenças na escrita: "[...] estas três maneiras de escrever correspondem com muita exatidão aos três diversos estados sob os quais se podem considerar os homens reunidos em naçōes. A pintura dos objetos convém aos povos selvagens; os signos das palavras e das proposiçóes aos povos bárbaros; e o alfabeto aos povos policiados." (ROUSSEAU, 1995, p. 385). 
fermentadora de paixôes que formam fagulhas de um sentimento gregário, essa maneira de viver despertou paixóes ociosas, inaugurando um período de sedentarismo e divisão entre tempo de trabalho e tempo de lazer, que acabam por estimular relações mais profundas e estáveis.

Finalmente, o terceiro modo de se viver é o do homem civilizado e agricultor [laboureur], isto é, o período da agricultura. Trata-se de uma atividade que demora a nascer, pois deve necessariamente "[...] conter todas as artes” (ROUSSEAU, 1995, p. 400), isto é, pressupõe também o conhecimento técnico sobre o manejo e a fundição de metais. É, portanto, um elemento cultural avançado. Introduzindo os germes que "[...] levam à propriedade, ao governo, às leis e, gradualmente, à miséria e aos crimes, que são inseparáveis, pela nossa espécie, da ciência do bem e o mal” (ROUSSEAU, 1995, p. 400), rompe com estado precedente de juventude do mundo, instaura a divisão do trabalho (e, assim, introduz uma nova relação com o homem e sua atividade, a qual não mais será baseada na autonomia, felicidade e autossuficiência) e conduz, por fim, o homem à sua degeneração: ao pacto proposto pelo rico e que deverá fundar a sociedade.

Goldschmidt argumenta que, no Segundo discurso, Rousseau abandona a tripartição "livresca" utilizada no Ensaio para designar os três modos possíveis de se viver do homem, para permanecer, então, com uma bipartição fundamental, na qual o primeiro e o segundo estágio (o da caça e o da arte pastoral, respectivamente) se fundem em um só, se pondo em oposição à agricultura. Ainda, a própria terminologia usada por Rousseau indica um abandono dessa tradicional tripartição: entre "bárbaros" e "selvagens", Rousseau, no Discurso, conserva apenas o segundo, referindo-se ao homem no estado de natureza e opondo-o ao homem em sociedade. (GOLDSCHMIDT, 1983, p. 419).?

Importa-nos aqui ressaltar que, não obstante se encontrem aglutinados no Segundo discurso, ambos os estágios da evoluçáo humana se fazem presentes

\footnotetext{
${ }^{6} \mathrm{O}$ termo é empregado eufemisticamente por Victor Goldschmidt. Transcrevemos o trecho, no original: "Dans l'Essai en effet, cette division des trois âges présente quelque chose de livresque, pour ne pas dire scolaire." (GOLDSCHMIDT, 1983, p. 418).

7 Dentre todos os elementos trazidos para ressaltar certas similitudes e diferenças entre o Segundo discurso e o Ensaio, Goldschmidt propõe que os três estágios da evolução humana são fundamentais para situar a data de escrita dos dois textos. Para Goldschmidt, o Ensaio é anterior ao Segundo discurso: "A comparação entre os dois escritos faz surgir, sobre o ponto em questão [a tripartiçáo dos modos de vida], mais divergências que semelhanças. Ela junta até mesmo, ao nosso ver, um índice suplementar e decisivo em favor da anterioridade do Ensaio em relação ao Discurso." (GOLDSCHMIDT, 1983, p. 148).
} 
no texto e comportam o surgimento da técnica e do trabalho e, tanto o primeiro quanto o segundo (este que, segundo Goldschmidt, é o resultado natural do primeiro) estão de acordo com a natureza e expressam uma relação de ordem antropológica que se liga à felicidade (GOLDSCHMIDT, 1983, p. 419). O trabalho seria de qualquer forma presente, assim, em um estado pré-social, e, mais ainda, atuaria de maneira marcante e decisiva no estado de juventude do mundo.

\section{Trabalho e ócio no ENSAio SObRe a origem das línguas}

No processo de determinaçáo das qualidades e outras condicionantes que caracterizarão Emílio, o preceptor, buscando condiçóes modelares de educação e a localização ideal de proveniência de seu pupilo, estabelece a seguinte polarização: “[...] no Norte os homens consomem muito em um solo ingrato; no merídio consomem pouco em um solo fértil. Nasce disto uma nova diferença que torna uns laboriosos e os outros contemplativos." (ROUSSEAU, 1969, p. 267, grifo nosso). Uma passagem no Segundo discurso, utilizando indústria como sinônimo de labor ou trabalho, também remete a essa diferença: "[...] observaria que, em geral, os povos do Norte são mais industriosos que aqueles do merídio, por menos poderem livrar-se de sê-lo." (ROUSSEAU, 1964, p. 143-144). É no Ensaio sobre a origem das linguas, entretanto, que Rousseau, tomando como referência essa ideia apresentada em Emílio e no Segundo discurso, desenvolve os desdobramentos dessa mesma polarização. Dessa forma, o Ensaio distingue dois extremos geográficos, onde as diferenças nas maneiras de se viver e de responder às exigências climáticas formarão os fundamentos nos quais as línguas irão adquirir determinada forma ${ }^{8}$ e nos quais as necessidades e as paixóes constituirão um composto de influência na evolução e na formação das línguas. $\mathrm{O}$ trabalho, a resposta humana à avareza natural e um contorno aos obstáculos do meio, desempenhará o papel essencial de fornecer condiçóes materiais necessárias para a habitação de um terreno que se demonstra pouco acolhedor. Contudo, a importância do trabalho e de sua organização se faz sentir diretamente na formação dos indivíduos e dos

\footnotetext{
${ }^{8}$ Para não nos desviarmos do escopo de nossa proposta, não será objeto de nossa atenção a análise pormenorizada ou o destrinchar da teoria linguística e musical que Rousseau apresenta, no Ensaio, embora por vezes esbarraremos em questốes concernentes ao tema, limitando-nos, quando necessário, apenas a algumas pontuaçóes. $\mathrm{O}$ assunto merece estudos próprios, e podemos destacadamente apontar duas grandes linhas de leitura do Ensaio: a de Bento Prado Júnior, com seu $A$ retórica de Rousseau (São Paulo: Cosac Naify, 2008), e aquela de Jacques Derrida, abordada em De la grammatologie (Paris: Minuit, 1967).
} 
povos, ou seja, trata-se de composto ativo na gênese antropológica e social. Premidos pela necessidade, os homens reúnem-se pelos primeiros trabalhos comuns: o labor cria os alicerces necessários que possibilitam os primeiros relacionamentos e que, posteriormente, formarão a base da sociedade iniciada. Já a formação de uma língua particular refletirá tanto as condições climáticas e geográficas na qual se moldou, como também as condiçóes materiais que a forjaram: em lugares onde a agitação laboriosa é muito necessária, a língua torna-se articulada e monótona'; por sua vez, regióes onde predominam paixôes ociosas e certa indolência é possível, a língua constitui-se com muitos acentos e energia. ${ }^{10}$

A diversidade geográfica estabelece em cada regiāo determinadas conformaçóes climáticas e de solo. Tendo em vista as imensas diferenças geográficas e entre climas que separam os dois polos, cada qual com suas influências externas características que acabam por forçar a coexistência, exige-se dos homens respostas diversas frente à situação na qual se encontram e, assim, diferentes tipos de trabalhos e atividades surgem entre grupos que se situam em localidades distintas ${ }^{11}$; variadas induistrias e labutas acabam por instaurar diferentes modos de vida. À necessidade que impõe a aproximação forçada, segue-se necessariamente a urgência do trabalho, fio de ligação dos primeiros agrupamentos, urdindo os contatos iniciais por meio de atividades coletivas que têm por fim compensar as dificuldades naturais. Nos termos de Derrida, "[...] a sociedade somente se cria para reparar os acidentes da natureza [...] Segue-se uma admirável descrição do trabalho do homem, cuja 'mão' retém a degradaçáo da natureza e 'atrasa este progresso'.” (DERRIDA, 1967, p. 367-368).

A polarização entre Norte e Sul explicará as diferenças e as origens das línguas: são as estaçôes e as diferenças da terra que darão ritmo a esse "movimento de cultura"12 que é a formação das línguas. O local de origem da língua, caracterizado por determinadas conformaçóes da natureza que o

\footnotetext{
9 Ou, ainda, uma língua "arrastada", morosa.

10 “Ora, em uma língua acentuada, são os sons, os acentos, as inflexões de toda espécie que compôem a maior energia da linguagem, e tornam uma frase, comum em outro contexto, própria somente ao lugar onde se encontra." (ROUSSEAU, 1995, p. 388).

${ }^{11} \mathrm{O}$ trecho que fundamenta esse argumento se encontra na seguinte passagem do Segundo discurso: "À medida que o gênero humano aumentou, as labutas [peines] se multiplicaram com os homens. A diferença dos terrenos, dos climas, das estaçôes, pode forçá-los a estabelecê-la nas maneiras de viver. Anos estéreis, invernos longos e rudes, veróes escaldantes que tudo consomem, exigiram deles uma nova indústria [industrie].” (ROUSSEAU, 1964, p. 165).

${ }^{12}$ É preciso ressalvar, entretanto, que a língua não é, de acordo com Derrida, um "simples elemento da cultura”, mas sim elemento que precede a própria formação da sociedade: é elemento, portanto, da
} 
distinguem (solo, clima, posição geográfica, estações), dá uma explicação da diferença e da própria origem:

A principal causa que as distingue é local, vem dos climas onde elas nascem e da maneira pela qual elas [as línguas] se formam; é a esta causa que é preciso remontar para conceber a diferença geral e característica que notamos entre as línguas do Meridiano e do Norte. (ROUSSEAU, 1995, p. 394).

São causas naturais, portanto, que explicam a gênese da primeira instituição social, a fala:

$\mathrm{O}$ uso e a necessidade fazem cada pessoa aprender a língua de seu país; mas o que faz que esta língua seja a de seu país e não de um outro? Para explicar isto, é preciso remontar a alguma razão pertinente ao local, e que seja anterior aos próprios costumes: a fala, sendo a primeira instituição social, só deve sua forma a causas naturais. (ROUSSEAU, 1995, p. 375).

As línguas do Norte estruturam-se utilizando primordialmente os moldes fornecidos pela necessidade: "[...] a primeira palavra não foi amaime [aimez-moi], mas ajudai-me [aidez-moi].” (ROUSSEAU, 1995, p. 408). Ante os rigores do clima, torna-se embaraçosa a satisfaçáo dos desejos, e o trabalho incessante, imprescindível para a sobrevivência, acabará por abafar as paixôes. É no seio da carência de produçóes naturais que nascem as línguas setentrionais. Porém, é a agitação laboriosa, resposta à necessidade, que aproximará os indivíduos: os homens superam as primeiras dificuldades graças a uma atividade coletiva, isto é, forçados pela necessidade, agrupam-se e realizam um trabalho coletivo que se opóe aos rigores da natureza. Ainda seguindo essa divisão entre o amor e o auxílio, entre a paixão e a necessidade, as formaçôes das línguas do Sul inclinam-se em direção ao primeiro extremo: são línguas que, em sua gênese, possuem como composto dominante as paixôes ${ }^{13}$ (ROUSSEAU, 1995, p. 407).

A primeira aproximaçáo pelo trabalho que ocorre no Norte, resposta aos apelos da necessidade, também vale para os lugares quentes, como nas regiôes áridas, nas quais os homens reúnem sua força e o trabalho de suas

\footnotetext{
"instituição em geral" e constrói a estrutura social. Surgindo antes da sociedade, ela é pré-cultural e suas causas são, desse modo, naturais (DERRIDA, 1967, p. 310-313).

13 "Em uma palavra, nos climas doces, nos terrenos férteis, foi preciso toda vivacidade das paixôes agradáveis para começar a fazer falar os habitantes.” (ROUSSEAU, 1995, p. 407).
} 
mãos para cavar poços e utilizá-los de maneira partilhada: essa atividade comum, fruto de um trabalho e uma reunião necessária para a superação de obstáculos da natureza, é que terá sido, diz Rousseau, a condição de possibilidade de formação das sociedades ${ }^{14}$ :

Nas regióes áridas foi preciso cooperaçáo para furar poços e para abrir canais a fim de dessedentar os animais. Nelas veem-se homens associados desde tempos quase imemoriais, pois ou a região continuaria deserta ou entấo o trabalho humano a tornaria habitável. (ROUSSEAU, 1995, p. 403, grifo nosso).

Nos países meridionais, onde o clima é quente, as primeiras atividades humanas concentram-se na dominação, controle e extração da água, trabalhos necessários e que tornam uma região estéril em local habitável: "Quanto aos países áridos", assinala Rousseau, "[...] somente são habitáveis pelos sangradouros e pelos canais que os homens tiraram dos rios." (ROUSSEAU, 1995, p. 405). É preciso que, através do trabalho humano, os homens interfiram no curso dos rios, construam poços e, modificando as disposiçóes naturais, criem novos afluxos e dutos, deslocando novos braços de rios e dos mares, capazes de irrigar a terra. Essa atividade essencial de desvio e de transformação da natureza somente pode ser feita pelo trabalho: “[...] antes do trabalho humano, as fontes, mal distribuídas, espalhavam-se mais desigualmente, fertilizavam menos a terra e saciavam mais dificilmente os habitantes." (ROUSSEAU, 1995, p. 405, grifo nosso). Rousseau recorre à história, ao exemplo de alguns países que podem servir como modelos concretos que reforçam essa argumentação:

A Pérsia inteira quase só subsiste por este artifício [os canais]; a China formiga de gente com a ajuda de seus numerosos canais; sem estes, os Países Baixos seriam inundados pelos rios, como, sem os diques, o seriam pelo mar; o Egito, o mais fértil país da terra, só é habitável pelo trabalho humano. (ROUSSEAU, 1995, p. 405, grifo nosso).

É somente o trabalho que, contrapondo-se a um meio ambiente pouco acolhedor, é capaz de transformar as condiçôes do meio, tornando um clima hostil em um lugar próprio à habitação e à vida: só o trabalho e a técnica

\footnotetext{
${ }^{14}$ A habitação, nos países de solo infértil, só é possível mediante a irrigação da terra e, portanto, não havendo nenhum sistema ou desvio que permita uma fruição dos recursos hidráulicos, torna-se impossível o povoamento e a ocupação da região, como veremos mais adiante.
} 
permitem ao homem a adaptação aos mais diversos ambientes, podendo, assim, suprir aquilo que lhe falta e compensar o que o corpo não pode realizar - e, desse modo, o meio ambiente já não é um empecilho intransponível. ${ }^{15}$ É em torno do trabalho comum, resposta à necessidade que agrupa e une os homens, que são construídas as bases materiais para o nascimento das sociedades e das línguas nos países quentes: "Nos lugares áridos, onde somente os poços forneciam água, foi preciso reunir-se para cavá-los, ou pelo menos entrar em acordo sobre seu uso. Esta deve ter sido a origem das sociedades e das línguas dos países quentes." (ROUSSEAU, 1995, p. 405).

Os poços e os locais de água, artifícios construídos através da atividade transformadora orquestrada sob a batuta do trabalho humano, formam, portanto, os primeiros espaços onde os contatos se travam duradouramente, onde os entreolhares se prolongam e nos quais "[...] se formam os primeiros laços das famílias." (ROUSSEAU, 1995, p. 405). A companhia do semelhante passa a se tornar prazerosa e desejada, a ferocidade se arrefece e o selvagem, aos poucos, se apaga para dar lugar ao bárbaro. ${ }^{16} \mathrm{O}$ trabalho, desse modo, cria as condiçóes materiais necessárias para o encontro e, assim, para o surgimento de novos sentimentos, preparando o terreno e o tempo preciso para o exercício da arte pastoril, propiciando o cultivo de paixóes ociosas e de um tempo de repouso.

Mas, no Sul, "[...] a natureza faz tanto pelos habitantes que eles quase nada têm a fazer” (ROUSSEAU, 1995, p. 408), possibilitando longos períodos nos quais é possível o intervalo entre as labutas. $\mathrm{O}$ tempo de sedentarização, isto é, os períodos fora do tempo de trabalho, permitem o espaço partilhado, nos quais os olhares se cruzam, formam um solo comum, no qual os encontros se tornam frequentes e agradáveis, provocando o desabrochar de novas paixóes e do amor. O trabalho e a técnica, criando o espaço e as condiçóes essenciais para a festa em torno da água, favorecem a fruiçáo tranquila do tempo que propicia os encontros, duraçáo que desperta o amor e que tece as primeiras costuras formadoras de um povo: "[...] tal foi, enfim, o verdadeiro berço dos povos - do puro cristal das fontes saíram as primeiras chamas do amor." (ROUSSEAU, 1995, p. 406). Trata-se de uma relação com o tempo que é vislumbrada e ilustrada nos escritos autobiográficos:

\footnotetext{
${ }^{15} \mathrm{O}$ argumento é posto da seguinte forma por Denis Faïck: "[...] a natureza aceita a sobrevivência do homo faber, que dominou o acordo com o mundo graças ao artefato que universaliza seu biótipo [...] o trabalho amplia o território do homem, que não precisa mais ficar restrito a um só ambiente como os animais, mas tem agora a capacidade de ser nômade." (FAÏCK, 2009, p. 67).

16 "O coração emocionou-se com esses novos objetos, uma atração desconhecida o tornava menos selvagens, ele sentia o prazer de não estar só.” (ROUSSEAU, 1995, p. 406).
} 
Jean-Jacques é indolente, preguiçoso como todos os contemplativos: mas esta preguiça está somente em sua cabeça. Ele não pensa senão com esforço, ele se fatiga a pensar [...] Entretanto, ele é vivo, laborioso à sua maneira. Ele náo pode sofrer uma ociosidade absoluta: é preciso que suas mãos, seus pés, seus dedos se mexam, que seu corpo esteja em exercício e que sua cabeça permaneça em repouso. Daí vem sua paixão pela caminhada; ele está em movimento sem ser obrigado a pensar. Em seus devaneios náo se é ativo [...] No mais, detesta a coerção tanto quanto ama a ocupação. $\mathrm{O}$ trabalho não lhe custa nada desde que possa fazê-lo em seu tempo, e não no dos outros. Conduz sem esforço o jugo da necessidade das coisas, mas não o da vontade dos homens. Gostará mais de fazer uma tarefa dobrada tomando seu tempo que uma simples em um momento prescrito. (ROUSSEAU, 1959, p. 845).

E, mais adiante, Rousseau relata uma nova experiência com o tempo: o experimento de, tendo-se desfeito de seu relógio, não ser esmagado pela pressão dos ponteiros, que, coercitivamente, também contam o tempo de produção:

Um dos momentos mais doces de sua vida foi quando, renunciando a todo projeto de fortuna para viver no dia-a-dia, ele se desfez de seu relógio. "Graças aos céus", gritou ele em um acesso de alegria, "nunca mais precisarei saber que horas são!” (ROUSSEAU, 1959, p. 845-846).

Essas passagens nos auxiliam a ilustrar a concepção de tempo também presente nesse período de transição que ocorre nas regiôes do Sul: "[...] nesta época feliz, onde nada marcava as horas, nada os obrigava a contá-las: o tempo não tinha outra medida que não o divertimento e o tédio." (ROUSSEAU, 1995, p. 405). Sem exercerem suas ocupaçóes mediante um tempo imposto pelo outro, o trabalho torna-se fonte de contentamento e prazer, atividade capaz de prover autossuficiência e ser exercida com autonomia.

Esse trabalho presente no estado de natureza, entretanto, não pressupóe divisão (somente com a invenção da metalurgia e a agricultura, ocorrerá a divisão), nem uma atividade penosa e imposta pelo outro; tampouco pressupóe alienação ou subordinação. A organização das tarefas realiza-se de maneira espontânea, marcada ao mesmo tempo pela autonomia do indivíduo e pelo caráter coletivo das obras. Não é necessário nenhum tipo de previdência ou cálculo interessado, que não compóem necessariamente a essência do trabalho: a previdência, acessório que posteriormente se agrega ao trabalho, ocorrerá apenas no momento do surgimento da agricultura e da metalurgia; no estado agora examinado, o homem permanece ainda com sua prudência maquinal, isto é, 
com alguma noção acerca do futuro que, todavia, é ainda muito restrita. Cada qual realiza seu labor à sua própria hora, sem exercer um esforço desagradável e nem mesmo com necessidade de qualquer espécie de acordo; em um clima ameno e de natureza mais amigável, as necessidades eram menos urgentes:

Podiam levar alguns homens a contribuírem para trabalhos comuns: um começava o tanque da fonte e, em seguida, o outro terminava, frequentemente sem ter tido menor necessidade do acordo e algumas vezes mesmo sem terem se visto. (ROUSSEAU, 1995, p. 407).

É a hostilidade da natureza e os diferentes graus de dificuldades que se apresentam pelo meio ambiente que irão determinar a quantidade, isto é, o tempo, e a espécie de trabalho necessário para que as condiçóes exteriores se tornem mais adequadas à sobrevivência. $\mathrm{O}$ tempo de trabalho exigido no Norte, por exemplo, é maior que no do Sul ${ }^{17}$ (ROUSSEAU, 1995, p. 400). No Norte, as intempéries mostram-se mais cruéis e somente com muito trabalho as dificuldades impostas pelo meio se dobram e se modificam através do labor humano. Diante do implacável frio, é preciso demonstrar um grande vigor físico e um trabalho quase incessante, para que a natureza se transforme e a vida seja possível: a debilidade e a inação significam a morte. ${ }^{18} \mathrm{~A}$ fim de adaptar-se para sobreviver, e já posta em ação a perfectibilidade, os homens passam a maior parte do tempo a construir e reconstruir artifícios, a trabalhar dia após dia contra os mesmos obstáculos, pois o inverno, intercalado apenas por um efêmero período de calor, sempre retorna para exigir novas forças dos braços. Dessa maneira,

[n]estes horríveis climas onde tudo é morto durante nove meses do ano, onde o sol somente aquece o ar durante poucas semanas para mostrar aos habitantes de quais bens estáo privados e para prolongar sua miséria; nestes lugares onde a terra nada dá senão a custa de muito trabalho e onde a fonte da vida parece estar mais nos braços que no coração, os homens, sem cessar ocupados em prover sua subsistência, dificilmente pensavam em laços mais doces. (ROUSSEAU, 1995, p. 408, grifo nosso).

\footnotetext{
17 "Os climas doces, os países vigorosos e férteis, foram os primeiros a serem povoados e os últimos onde as naçôes se formaram, pois os homens ali podiam mais facilmente dispensar uns aos outros, e as necessidades que fazem nascer a sociedade fizeram neles se sentir mais tarde." (ROUSSEAU, 1995, p. 400). Como também pudemos ler em Emílio, os homens do Norte são mais laboriosos (pois o clima assim exige), enquanto os povos do Sul são mais contemplativos.

${ }^{18}$ Rousseau escreve que, "[...] ainda que os homens se acostumem às intempéries do ar, ao frio, à doença, mesmo à fome, há, entretanto, um ponto onde a natureza sucumbe. Nas garras destas cruéis provocaçōes, tudo aquilo que é débil perece; todo o resto ganha força, e não há meio termo entre o vigor e a morte." (ROUSSEAU, 1995, p. 407).
} 
A fonte da vida parece estar mais nos braços: a sobrevivência só é possível com a labuta, e a vida pulsa através da atividade laboriosa. Esse trabalho constante - esse labor quase ininterrupto contra a violência do meio - é uma marca distintiva na formação dos povos do Norte, tornando-os um povo eminentemente laborioso (pois, como vimos acima, na passagem de Emílio, os povos do Norte caracterizam-se por serem laboriosos), fator que imprime uma feição indelével nos indivíduos e nos agrupamentos nascentes desses locais, deixando traços permanentes na história das naçôes, os quais acabarão por se constituir em tais regióes. Será o trabalho o ponto de gravidade que articula e favorece a formaçáo das sociedades do Norte, com indivíduos que se unem para combater as intempéries. ${ }^{19}$ Assim,

[a] ociosidade que alimenta as paixöes dá lugar ao trabalho, que as reprime. Antes de pensar em viver feliz, era preciso pensar em viver. A necessidade mútua unindo os homens bem melhor que o sentimento teria feito, $a$ sociedade só se forma pela indústria, o contínuo perigo de perecer não permitia que se limitasse à língua do gesto. (ROUSSEAU, 1995, p. 408, grifo nosso).

As línguas do Norte são dotadas de uma clareza impositiva, pois, desde logo, é preciso fazer-se entender. As articulações tomam o lugar da energia e do acento verificado nas línguas do $\mathrm{Sul}^{20}$, e o desenvolvimento da linguagem setentrional, por sua vez, carrega indelevelmente a marca do frio invernal da natureza: "[...] a língua torna-se mais exata, mais clara, porém mais arrastada, mais surda e mais fria." (ROUSSEAU, 1995, p. 384). O pedido de ajuda antecede o pedido de amor e o trabalho termina por reprimir as paixóes: diferente das regiôes meridionais, nas quais predominam as paixôes "[...] voluptuosas, que vêm do amor e da languidez" (ROUSSEAU, 1995, p. 408) - essa languidez que é fruto da indolência (DERRIDA, 1967, p. 320), os homens do Norte, náo eliminando suas paixóes, entretanto, as possuem em outro tipo:

\footnotetext{
${ }^{19}$ Derrida nos lembra que “[...] normalmente, a necessidade separa os homens no lugar de aproximálos; no Norte, ela é a origem da sociedade.” (DERRIDA, 1967, p. 319). As necessidades, todavia, são superadas pelo trabalho coletivo, que une os homens em prol de uma reparaçáo comum.

${ }^{20}$ Em comparação à formação das línguas do Norte às línguas do Sul, Rousseau escreve: "Nada havia para se fazer sentir, tudo havia para se fazer entender: não se tratava, portanto, de energia, mas de clareza. O acento, que o coração não fornecia, foi substituído pelas articulaçôes fortes e sensíveis, e se houve na forma da linguagem qualquer impressão natural, esta impressão contribuiu ainda mais para a sua dureza." (ROUSSEAU, 1995, p. 408).
} 
Com efeito, os homens setentrionais não deixam de possuir paixões, mas as possuem de outra espécie (...) No Norte, onde os habitantes consomem tanto em um solo ingrato, os homens, submetidos a tantas necessidades, são fáceis de irritar; tudo o que se faz à sua volta inquieta-os: como eles só subsistem com labuta [peine], quanto mais são pobres, mais se apegam ao que têm; aproximá-los é atentar contra sua vida. Daí vem esse temperamento irascível, táo pronto para se tornar em furor contra tudo que os fere. Assim, suas vozes mais naturais são as da cólera e das ameaças, e estas vozes sempre se acompanham de articulaçóes fortes que as tornam duras e barulhentas. (ROUSSEAU, 1995, p. 408).

O meio ambiente avaro do Norte impóe seu ritmo, fazendo com que a necessidade predomine sobre as paixóes: enquanto, nos climas meridionais, de natureza abundante e mais generosa (e, portanto, que exige menos tempo de trabalho e possibilita a dedicação de mais horas para o lazer e a inação), as necessidades nascem das paixóes, nas regióes setentrionais tudo se inverte: encontram-se climas frios e compostos por uma natureza ameaçadora e mesquinha, recusando-se a entregar suas produçóes, e as paixóes nascem das necessidades; as línguas, por sua vez, "[...] filhas tristes da necessidade, ressentem-se de sua dura origem.” (ROUSSEAU, 1995, p. 407).

Acuados pelos obstáculos que se impóem incessantemente e pelas revoluçóes que insistem em destruir repetidamente todo o trabalho anterior realizado, os homens são obrigados a se organizar coletivamente e de maneira constante para trabalhar: "O trabalho", escreve Starobinski, "[...] implica uma duração que se organiza no contato com o obstáculo, a reflexão é o agente dessa organização." (STAROBINSKI, 1964, p. LX). A mudança inicial não vem de dentro: é o constrangimento do exterior, realizado pelo meio, que força os indivíduos primeiramente a se agrupar e a estabelecer determinados acordos, forçando-os a recolher provisóes comuns: "[...] forçados a se abastecerem para o inverno, veem-se os habitantes no caso de se auxiliarem mutuamente, coagidos a estabelecer entre eles alguma espécie de convenção." (ROUSSEAU, 1995, p. 402).

Mas, assim como no Sul, é no espaço comum, criado mais uma vez pelas condiçóes materiais oferecidas pelo trabalho, que os laços humanos se apertam. "Quando se tornam impossíveis as expediçóes e o rigor do frio os faz parar, o tédio liga-os tanto quanto a necessidade." (ROUSSEAU, 1995, p. 402, grifo nosso). Mais uma vez, é fora do tempo de labor (todavia, ainda assim, um tempo que é uma condição propiciada pelo próprio trabalho), em 
um local onde os encontros se tornam possíveis, que os relacionamentos e as paixôes florescem. Contudo, a festa e os entreolhares não se dão em torno do poço ou da água, mas sim ao redor da fogueira, do foyer, um lar comum que conduz aos primeiros sentimentos de humanidade:

Nem o estômago nem os intestinos do homem são feitos para digerir a carne crua; em geral, seu gosto não a suporta [...] Ao uso do fogo, necessário para cozinhá-las, junta-se o prazer que ele dá à vista e o calor agradável que dá ao corpo. $\mathrm{O}$ aspecto da chama, que faz os animais fugirem, atrai o homem. Reúnem-se em torno de uma fogueira comum, ai se fazem festins, ai se dança; os doces laços do hábito aí insensivelmente aproximam o homem de seus semelhantes, e sobre esta fogueira rústica queima o fogo sagrado que leva ao fundo dos coraçôes o primeiro sentimento de humanidade. (ROUSSEAU, 1995, p. 403, grifo nosso).

A reunião, dessa forma, ocorre em um tempo forçado e não escolhido pelos indivíduos (diferente, por exemplo, do Sul, no qual os encontros acontecem de maneira mais espontânea): uma força externa impóe o tempo de contato e os coage à união. A duração dessa aproximação é também estabelecida pelo meio: os breves encontros do Norte, que engendram relaçóes e sentimentos em torno do fogo e são temperados com o tédio, são bruscamente interrompidos pelo grito agudo da necessidade, incomodada pela hostilidade da natureza: "[...] reúnem-se no inverno em suas cavernas e, no verão, não mais se conhecem.” (ROUSSEAU, 1995, p. 402-403). É necessário, após esse retiro forçado para os abrigos rústicos, que novamente voltem aos trabalhos: a natureza permite pouco descanso, e as necessidades precisam, novamente, encontrar sua satisfação. $\mathrm{O}$ desenrolar das paixóes tem sua continuidade quebrada pela necessidade da volta ao trabalho.

$\mathrm{O}$ trabalho não precisa aguardar o nascimento da sociedade, e tampouco o desenvolvimento da metalurgia e da agricultura, para obter sua certidão de existência e adquirir seu nome: a importância capital que ele desempenha, na construção da gênese antropológica e social pensada por Rousseau, e sua fundamental atuação no estado de natureza, o credencia à condição de conceito filosófico fundamental. ${ }^{21} \mathrm{O}$ trabalho é, na verdade, condição de possibilidade da sociedade e da vida, fornecedor de condiçóes materiais imprescindíveis para a sobrevivência e agente que liga e catalisa as primeiras aproximaçóes

${ }^{21}$ Para Faïck (2009, p. 270), "[...] o pensamento de Rousseau sobre o trabalho lhe confere um estatuto fundamental. Ele é, de fato, uma noção filosófica, antropológica, sociológica e econômica essencial, sem estar maculado do caráter negativo que parasita toda tentativa de pensá-lo como um bem." 
humanas. Assim como a linguagem se dispóe como elemento que compóe a questão da formação social, o trabalho se apresenta como instituição anterior ao estado civil e como atividade que arquiteta e organiza a estrutura social, encontrando-se, ainda, no meio termo do estado de natureza que precede a fundação da sociedade, e trata-se, da mesma forma, de atividade que encontra em seus fundamentos causas naturais. Isso significa dizer que o trabalho não é somente elemento de cultura que surge após o contrato, mas sim de atividade cujas raízes são naturais, isto é, atividade que, se não é propriamente uma caracteristica ou fato natural que se encontra nas origens, é, entretanto, um fato humano, próprio da natureza humana. ${ }^{22}$

VARGAS, T. Between the laborious and the contemplative: the role of the notions of labor and idleness in Rousseau's Essay on the Origin of Languages. Trans/form/ação, Marília, v. 41, n. 1, p. 81-98, Jan./Mar., 2018.

\begin{abstract}
In the Essay on the Origin of Languages, a text posthumously published in 1781, Rousseau reflects on aspects of anthropological and social formation in light of the different climatic and geographical settings in which men live. The aim of this paper is to examine the importance of the notions of labor (travail) and idleness (oisivété) for elements that, in the Essay, constitute the anthropology developed by Rousseau. To this end, we show how the various difficulties imposed by nature require varied responses to obstacles imposed by the environment. Establishing a polarization between North and South through a description of multiple types of human labor, we can see how such activities will shape, in their own way, the different languages and passions that characterize the northern and southern individuals: if in the North labor represses the passions, in the South one may find a condition that better suits men's natural idleness, an anthropological attribute which is essential to the natural system advanced by Rousseau. Lastly, we emphasize how the importance of labor as a response to different climatic-geographic conditions also plays a role in the formation of peoples, creating material conditions and possible spaces of companionship, thus becoming an essential element in the complex that forms the genesis of the anthropological and social thought of Rousseau.
\end{abstract}

KEYworDs: Labor, Idleness, Essay on the Origin of Languages, Rousseau, Anthropology.

\title{
REFERÊNCIAS
}

ARISTÓTELES. La politique. Tome I. Traduction par J. Tricot. Paris: J. Vrin, 1962.

DERRIDA, J. De la grammatologie. Paris: Minuit, 1967.

FAÏCK, D. Le travail: anthropologie et politique: Essai sur Rousseau. Genève: Droz, 2009.

${ }^{22}$ E o mesmo raciocínio vale para a instituição da família, como nos lembra Yves Vargas: a família não é um fato humano artificial, mas um fato da natureza humana e "[...] isto não é contraditório, pois a natureza humana conhece diferentes acepçōes, diferentes etapas.” (VARGAS, 2005, p. 21). 
FEBVRE, L. La terre et l'évolution humaine. Paris: Albin Michel, 1949.

GOLDSCHMIDT, V. Anthropologie et politique: les principes du système de Rousseau. Paris: J. Vrin, 1983.

PRADO JÚNIOR, B. A retórica de Rousseau e outros ensaios. Organização e apresentação de Luiz Fernando Franklin de Matos. Traduçáo de Cristina Prado. São Paulo: Cosac Naify, 2008.

ROUSSEAU, J-J. Rousseau, Juge de Jean-Jacques. In: Euvres complètes de Jean-Jacques Rousseau. Tomo I: les confessions: autres textes autobiographiques. Paris: Gallimard; Bibliothèque de la Pléiade, 1959.

. Discours sur l'origine et les fondements de l'inégalité parmi les hommes. In: Euvres complètes de Jean-Jacques Rousseau. Tomo III: du contrat social: écrits politiques. Paris: Gallimard; Bibliothèque de la Pléiade, 1964.

. Émile ou de l'éducation. In: Euvres complètes de Jean-Jacques Rousseau. Tomo IV: Émile: éducation, morale, botanique. Paris: Gallimard ; Bibliothèque de la Pléiade, 1969.

. Essai sur l'origine des langues. In: Euvres complètes de Jean-Jacques Rousseau.

Tomo V: écrits sur la musique, la langue et le théâtre. Paris: Gallimard; Bibliothèque de la Pléiade, 1995.

SALINAS FORTES, L. R. O Bom selvagem. São Paulo: Humanitas; Discurso Editorial, 2007.

STAROBINSKI, J. Introduction: discours sur «l'origine de l'inégalité». In: ROUSSEAU, J-J. Euvres complètes. Tomo III. Paris: Gallimard, 1964.

. Introduction: essai sur l'origine des langues. In: ROUSSEAU, J-J. CEuvres complètes. Tomo V. Paris: Gallimard, 1995.

VARGAS, Y. Les promenades matérialistes de Jean-Jacques Rousseau. Pantin: Les Temps de Cerises, 2005.

Recebido: 11/08/2015

Aceito: 26/07/2016 
VARGAS, T. 